\title{
Uma análise crítica da teoria quantitativa da moeda
}

\author{
Mário Jorge Mendonça*
}

RESUMO - Neste artigo se elabora uma análise crítica da teoria quantitativa da moeda com ênfase na abordagem da Escola Austríaca de Economia. Para tal, perfazemos uma revisão histórica desde a elaboração original desta teoria feita por Hume (1752) e formalização engendrada de Fisher (1911), até sua incorporação dentro da síntese neoclássica em Friedman (1958). Conforme procuramos mostrar, a ideia de neutralidade da moeda mesmo no longo prazo, assim como a existência de uma quantidade ótima de dinheiro, são verdadeiras quimeras. Tais ideias desconsideram por completo a forma pela qual uma expansão monetária atua entre os agentes econômicos.

Palavras-chave: Teoria quantitativa da moeda. Neutralidade da moeda. Efeito Fisher. Quantidade ótima de moeda.

\section{ORIGEM E EVOLUÇÃO HISTÓRICA}

Existe uma pergunta crucial em teoria econômica: o que acontece numa economia quando o volume de moeda se altera? $\mathrm{Na}$ verdade o que se deseja responder é qual o efeito de uma mudança da quantidade de moeda sobre os preços, o emprego e a produção de bens. Esta questão tem sido objeto de estudo ao longo da história por parte de grandes economistas. Existe certo consenso que foi David Hume, em dois brilhantes ensaios escritos em 1752, Of Money e $O f$ Interest, um dos primeiros economistas a dar uma resposta analiticamente consistente a tal indagação. Sua resposta foi, a grosso modo, a seguinte: durante algum tempo, a produção de bens e serviços assim como o nível de emprego se alteram; contudo, com o decorrer do tempo, todo o efeito da alteração do estoque de moeda é repassado para os preços. Esta ideia deu origem ao que se conhece hoje como a teoria da quantidade de moeda (TQM) ou dinheiro. Em outras palavras, esta teoria pode ser definida da seguinte forma e com base em duas afirmações: primeiro, a doutrina de que uma variação no número de unidades de moeda em circulação terá efeito proporcional sobre todos os preços expressos em termos da mesma unidade monetária; segundo, tal mudança no estoque de moeda não implica em nenhum efeito real sobre a economia. Esta última proposição ficou conhecida como hipótese da neutralidade da moeda. De acordo com Hume:

\footnotetext{
* Mestre em Economia pela Universidade Federal Fluminense. É técnico de planejamento e pesquisa da Diretoria de Estudos e Políticas Macroeconômicas do Instituto de Pesquisa Econômica Aplicada. Endereço eletrônico: mario.mendonca@ipea.gov.br.
} 
O dinheiro não é nada além da representação do trabalho e dos produtos de uma economia, servindo somente como um método da avaliação ou de mensuração. Onde a moeda se encontra em maior abundância, maior a quantidade que se exige dela para representar a mesma quantidade de bens, não podendo ter efeito algum, bom ou mau, além de simplesmente alterar a escrita dos comerciantes. (HUME, 1752).

Muito embora Hume (1752) tenha deixado claro que isso não deveria ser entendido como ponto de maior relevância em sua teoria, ele percebeu a existência de efeitos transitórios sobre os preços, emprego e quantidade de bens em circulação antes que o estado da economia alcance o nível de equilíbrio em consequência de uma variação no estoque monetário. Tais efeitos se dariam pelo fato de que a mudança na quantidade de moeda não acontece de modo uniforme na economia. Alguns agentes são privilegiados por que se beneficiam de ter em seu domínio uma maior quantidade de moeda antes dos demais agentes da economia. Nas palavras do próprio Hume:

\begin{abstract}
Quando certa quantidade de moeda é importada por uma nação, de início ela não se dispersa, permanecendo confinada nos cofres de algumas poucas pessoas que imediatamente procuram tirar vantagens disso. São industriais ou negociantes [...] que se tornam capazes de empregar mais trabalhadores os quais não demandam inicialmente por maiores remunerações [...] Esses trabalhadores agora com mais dinheiro podem comer e beber melhor. $\mathrm{O}$ fazendeiro e o jardineiro percebendo que suas mercadorias estão sendo levadas, esforçam-se em conseguir mais bens de consumo [...] É fácil perceber que a trajetória da moeda em seu percurso acelera a diligência dos indivíduos antes que o preço do trabalho se eleve. (HUME, 1752).
\end{abstract}

As ideias de Hume permanecem no centro de debate em macroeconomia até os dias atuais. Tomando por base a corrente mainstream, existe certo consenso de que a moeda é de fato neutra ou pelo menos provoca forte impacto sobre os preços no longo prazo. McCandless e Weber (1995), examinado dados para uma amostra de 110 países ao longo de 30 anos, mostram que a taxa de crescimento do estoque monetário para três diferentes definições de moeda e para duas amostras de países é altamente correlacionada com o nível de preços. Este estudo mostrou ainda que, exceto para uma subamostra de países da OECD, a taxa de crescimento da moeda assim como a taxa de inflação são não correlacionadas com o produto real. Estas duas verificações empíricas estão em conformidade com as predições da teoria quantitativa da moeda. Entretanto, no que se refere ao curto prazo não existe uma ideia consensual. De um lado, existem as teorias de cunho keynesiano suportadas pela ideia de rigidez nominal a nível dos salários (KEYNES, 1936) ou mesmo dos preços (FISHER, 1977). Mesmo um economista de tendência monetarista como Friedman (1958), com sua versão aceleracionista da curva de 
Phillips, assinala a existência de efeitos transitórios sobre o produto e o emprego em decorrência de uma expansão monetária, enquanto Lucas (1969a, b) chama atenção de que uma alteração do estoque de moeda produz efeitos reais somente no caso de uma mudança inesperada para os agentes econômicos.

Tendo em vista o que foi dito acima, podemos dizer que Hume (1752a, b) sistematizou os principais preceitos do monetarismo na medida em que elaborou uma teoria que reconhece seus pilares fundamentais, como a neutralidade da moeda no longo prazo permitindo a existência de efeitos transitórios no curto prazo. De acordo com Lucas (1995), o arcabouço teórico formulado por Hume é falho porque não identifica o mecanismo pelo qual a expansão monetária provoca efeito sobre as variáveis reais como o produto e o emprego, ou seja, na teoria exposta por Hume não está explícito qual é o mecanismo de transmissão pelo qual a moeda provoca efeito real sobre a economia. Contudo, acreditamos que a crítica feita por Lucas (1996) quanto a este ponto é de certo modo injusta. Hume (1752a) deixa clara a ideia, muito bem explorada mais tarde por Mises $(1912,1966)$, de que quando ocorre um aumento na quantidade de moeda, a forma como esta quantidade se espalha pela economia não acontece de modo uniforme. Por exemplo, suponha que o governo considere como objeto de política o estímulo de determinado setor, digamos o setor imobiliário, pelo aumento do crédito. Supondo ainda que a criação de crédito seja operacionalizada pela criação de moeda. Neste caso, não é difícil imaginar que determinados grupos de indivíduos como mutuários, empresas de construção, força de trabalho ligada a este setor, além de outros, irão se beneficiar do direcionamento do crédito ${ }^{1}$.

Foi Irving Fisher, numa obra intitulada The Purchasing Power of Money, publicada em 1911, que deu contorno mais preciso à teoria quantitativa da moeda. Seu objetivo era explicar os determinantes do poder de compra da moeda (PCM), isto é, o quanto se pode adquirir dado uma quantidade de moeda tendo em vista que o PCM é o recíproco do nível de preços. Quanto menor os preços, maior serão as quantidades que podem ser compradas com certa quantidade de dinheiro e, portanto, maior o poder de compra do dinheiro. Contrariamente, quanto maiores os preços, menor a quantidade de bens que pode ser comprada com a mesma quantidade de moeda.

A exposição se inicia pela definição de que a quantidade gasta em bens ( $E$ ) numa economia em certo período é determinada pelo saldo médio de moeda em circulação $(M)$ observado no mesmo período de tempo multiplicado por uma variável denominada velocidade de

1 Os benefícios para estes grupos podem ser classificados em várias ordens. Em geral, o crédito subsidiado dado pelo governo é direcionado para determinada classe de indivíduos. Além disso, estes mutuários irão se beneficiar da futura valorização do imóvel. As empresas ligadas a este setor se beneficiarão do lucro, enquanto a mão de obra do aumento do salário real em comparação à remuneração paga nos demais setores. 
circulação da moeda $(V)$, que indica quantas vezes este saldo girou na economia. Assim temos que $E=M V$. Por outro lado, toda transação envolve preço e quantidade. A soma gasta em cada mercadoria pode ser expressa pelo preço médio $\left(P_{i}\right)$ de cada uma delas versus a quantidade transacionada $\left(T_{i}\right)$. O total despendido em bens $(T)$ seria o somatório do que é gasto com cada bem $\sum_{i} P_{i} T_{i}$. Fisher admite a existência de duas outras variáveis: a média ponderada de todos os preços $(P)$, isto é, o nível geral de preços e $T=\sum_{i} T_{i}$. Temos então que $\sum_{i} P_{i} T_{i}=P T$. Como o valor total gasto na compra de bens $(E)$ deve ser necessariamente igual ao valor desses mesmos bens temos que:

$$
M V=P T
$$

Esta expressão define a famosa identidade de Fisher (1911), pois um lado tem que necessariamente ser igual ao outro. Contudo, de acordo com Fisher, ela serve para mostrar que o nível de preços varia: (i) diretamente em relação à quantidade de moeda; (ii) diretamente com a velocidade de circulação da moeda; e (iii) inversamente em relação ao volume de bens transacionados. Supondo que $V$ e $T$ permaneçam constantes, o item (i) formaliza a teoria quantitativa da moeda. Fisher ainda inclui na sua equação o que ele chama de moeda bancária, de modo que:

$$
M V+M^{\prime} V^{\prime}=P T
$$

Fisher tinha em mente que existe uma relação estável que diz que o estoque de moeda bancária é um múltiplo do total de moeda básica. Assim, quando este volume se altera continua valendo a ideia de que o nível de preço muda na mesma proporção.

A forma expandida da equação de Fisher serve para analisar os efeitos temporários de uma mudança no estoque de moeda. De acordo com Fisher (1911) “quando o estoque de moeda dobra repentinamente os efeitos iniciais e finais não são os mesmos". Uma vez terminado o processo, o nível de preços se multiplica por dois. Entretanto, durante o período de transição "antes que se alcance um novo equilíbrio os preços podem oscilar para cima e para baixo". Uma ideia fundamental em Fisher é a de que são os movimentos na taxa de juros induzidos pela inflação durante o período de transição que geram os ciclos econômicos. No clássico The Theory of Interest, de 1930, ele propôs o que se conhece hoje como efeito Fisher, que diz que a taxa de juros nominal se ajusta na mesma medida da taxa de inflação. Contudo, isso não acontece de modo imediato e a lentidão deste ajuste, segundo Fisher, é o cerne dos períodos de euforia e crise da economia. 
O modo pelo qual isso acontece pode ser ilustrado da seguinte forma. Inicialmente a taxa de juros se movimenta, mas não incorpora toda a mudança ocorrida nos preços devido a um aumento do estoque de moeda. Além do mais, os custos empresariais sobem, mas de modo menos acentuado que os preços, enquanto os títulos contraídos a taxa de juros fixa perdem valor frente à inflação. Assim, os lucros dos empresários aumentam. Percebendo isso, eles são incentivados a expandirem seus negócios, contraindo novos empréstimos. Como existe uma relação direta entre estes empréstimos e a criação de moeda bancária, $M^{\prime}$ (depósitos) cresce. Isso, de acordo com a TQM, gera novo impulso sobre o nível de preços. O processo somente tem fim quando a taxa de juros incorpora plenamente a taxa de inflação.

\section{AS INCONSISTÊNCIAS DA EQUAÇÃO DE FISHER}

Iremos nesta seção discutir alguns pontos que consideramos inconsistentes e falaciosos na equação de Fisher. Vejamos inicialmente o exemplo que aparece em Rothbard (1983). Consideremos uma mera transação, uma transação individual onde Smith compra dez libras de açúcar por 7 centavos cada libra. Uma troca foi realizada, Smith dando 70 centavos para Jones enquanto este transfere 10 libras de açúcar para Smith. Daí Fisher, de alguma maneira, deduz que "10 libras de açúcar foram tratadas como iguais a 70 centavos, e esse fato pode ser expresso da seguinte forma: 70 centavos $=10$ libras multiplicadas por 7 centavos cada libra". De acordo com a teoria subjetiva do valor, esta suposição de igualdade não é nenhum pouco evidente. Vejamos a seguinte questão: é razoável supor que "as 10 libras de açúcar são iguais aos 70 centavos"? Certamente não são para Smith, o comprador do açúcar. Ele comprou o açúcar simplesmente porque ele considerou as duas quantidades como desiguais em valor; para ele o valor do açúcar era maior do que o dos 70 centavos, e foi por isso que ele realizou a transação. $\mathrm{Na}$ outra ponta, Jones, o vendedor do açúcar, realizou a transação precisamente porque os valores dos dois bens eram desiguais na direção oposta, ou seja, ele valorou os 70 centavos mais do que o açúcar. Nunca há igualdade de valores por parte dos dois participantes. Como assinala Rothbard (1983), a ideia de que uma troca presuma algum tipo de igualdade foi uma ilusão da teoria econômica desde Aristóteles, e surpreende que Fisher, um expoente da teoria subjetiva do valor em muitos aspectos, tenha caído nesta antiga armadilha.

Como bem atesta Rothbard (1983), não há igualdade de valores entre dois bens trocados ou, como acontece nesse caso, entre o dinheiro e o bem. Mas para Fisher, a equação representa uma igualdade em valor entre o "lado monetário" e o "lado dos bens"; assim, Fisher afirma: 
O dinheiro total pago é igual em valor ao total valor dos bens comprados. A equação assim possui um lado monetário e um lado das mercadorias. O lado monetário é o total de dinheiro pago [...] O lado das mercadorias é constituído dos bens trocados multiplicados pelos seus respectivos preços. (FISHER, 1911).

Nós vimos, contudo, que mesmo numa troca individual, e deixando de lado o problema holístico das "trocas totais", não existe tal "igualdade" que nos diga algo sobre os fatos da vida econômica. Não há "valor-do-lado-monetário" igualando um "valor-do-lado-das-mercadorias". O sinal de igualdade é ilegítimo na equação de Fisher.

Outra questão que merece consideração se refere à possibilidade de obter variáveis agregadas que expressem algum sentido tais $P$ e $T$ que definimos acima. Como vimos, à luz da teoria subjetiva do valor mesmo para o caso individual de um único bem, a equação de troca de Fisher é falaciosa. Assim, devemos examinar se outras inconsistências aparecem no caso da equação expandida para toda a economia. Obviamente não há problema em somar a quantidade total de dinheiro gasto numa economia, mas o mesmo não ocorre para o lado da equação representativa do volume de bens. Acima definimos $T$ da seguinte forma $T=\sum_{i} T_{i}$. Como podemos somar, por exemplo, libras de açúcar com chapéus, libras de manteiga e assim por diante, e chegar a $T$ ? Obviamente, nenhuma adição desse tipo pode ser efetuada, e logo o $T$ da equação de Fisher, a quantidade física total, é um conceito que não pode ser usado em análise científica. Vejamos agora o caso da variável $P$. No pensamento de Fisher os preços não poderiam ser de alguma forma "ponderados" para nos dar um nível de preços? Infelizmente, frequentemente o conceito de uma média para preços é aplicado de modo falacioso. Não é difícil demonstrar que os preços jamais podem ser ponderados para mercadorias diferentes tal como é recomendado por Fisher.

Primeiro, devemos reconhecer que para que um conjunto de coisas possam ser ponderadas elas devem antes ser totalizadas. E para serem somadas, elas devem possuir uma unidade em comum. Apenas unidades homogêneas podem ser somadas. Um conceito usado por Fisher é o de média ponderada, definido da seguinte forma:

$$
P=\frac{\sum_{i} P_{i} T_{i}}{\sum_{i} T_{i}}
$$

Com os preços ponderados pelas quantidades de cada bem vendido, o problema no numerador está resolvido, mas quanto ao denominador? Os $P_{i} T_{i}$ são parcelas expressas em valores monetários, mas os $T_{i}$ são expressos em unidades distintas. Assim sendo, o conceito 
de nível de preços $P$ é completamente falacioso, e portanto é óbvio que o uso da equação de Fisher para revelar os determinantes dos preços também é falacioso. Assim sendo, a principal ideia da equação de Fisher, que postula que se $M$ duplica o mesmo acontece com $P$, é simplesmente falsa, pois esta variável não pode ser definida.

Do que foi dito, depreende-se que Fisher não foi bem sucedido na construção de $T$ a partir dos $T_{i}$ individuais, bem como $P$ com o uso dos $P_{i}$. Mas vejamos se ele é mais bem sucedido na elaboração da variável $V$. Também a velocidade de circulação da moeda não é uma variável independentemente definida. Fisher deriva $V$ como sendo igual em todos os instantes e em todos os casos a $E / M$. Entretanto, é sem sentido definir uma variável na equação a menos que ela possa ser definida independentemente dos outros termos na equação. Um grupo de economistas de Cambridge - Pigou, Robertson etc. - tentou reabilitar a equação de Fisher eliminando $V$ e substituindo a ideia de que a oferta total de dinheiro se iguala a demanda total por dinheiro. Entretanto, sua equação não é um avanço em particular, uma vez que mantém os conceitos holísticos de $P$ e $Q$, e seu ké meramente o recíproco de $V$, e sofre das deficiências do último.

\section{A FALÁCIA DA NEUTRALIDADE DA MOEDA}

Tratemos agora de demonstrar outra inconsistência da teoria quantitativa da moeda, ou seja, a falácia da neutralidade da moeda. De acordo com Mises (1912, 1966), o modo como a teoria microeconômica introduz a moeda em seu arcabouço teórico impede que se contemple a verdadeira forma de como a moeda opera dentro do sistema econômico. Neste modelo, o mecanismo pelo qual as transações se efetuam se baseia na suposição implícita de que prevalecem apenas as trocas diretas. Nesse cenário, os economistas estão descrevendo uma entidade puramente hipotética: um mercado sem trocas indiretas, sem um meio comum de trocas, isto é, um mercado sem moeda. Para apresentar o raciocínio a que se propõe, não há dúvidas de que esse método é o único possível, que a eliminação da moeda é necessária e que não se pode ir adiante sem essa ideia de um mercado com apenas trocas diretas. Isso seria válido apenas sob a hipótese de que a moeda, ao ser introduzida, não afetasse o resultado antes obtido. Foi dessa suposição de um mercado sem moeda que surgiu a falaciosa ideia da moeda neutra. Assim, como coloca Mises (1912), é necessário que os economistas entendam que esse é um conceito meramente hipotético, sem semelhança com a realidade. O mercado verdadeiro é necessariamente um mercado onde ocorrem trocas indiretas e transações monetárias.

Os economistas têm desenvolvido métodos para cálculo de índices de inflação com o intuito de mensurar as mudanças no poder de compra da moeda, mas não levaram em conside- 
ração que, no mundo real, os preços relativos de cada mercadoria estão em transição contínua. Os economistas ainda insistem na hipótese de que as consequências de uma mudança na demanda ou oferta de moeda implicam numa modificação proporcional e simultânea dos preços. O método dos números índices foi criado somente para fornecer uma maneira de possibilitar uma distinção entre dois fenômenos: o aumento dos preços em decorrência de alterações na demanda ou oferta de mercadorias e o aumento dos preços em decorrência de alterações na demanda ou oferta de moeda.

A errônea suposição da neutralidade da $\operatorname{moeda}^{2}$ é a raiz de todas as tentativas de se estabelecer a fórmula da chamada equação de troca. Ao lidar com tal equação, o economista assume que, se uma variável da equação é alterada, então consequentemente outras variáveis também serão correspondentemente alteradas. O problema é que os elementos da equação não representam itens da economia individual, mas sim itens de todo o sistema econômico, o que significa que as mudanças por ela descritas estão ocorrendo não com os indivíduos, mas no sistema econômico como um todo. Problemas monetários são problemas econômicos e precisam ser analisados da mesma forma que se analisam todos os outros problemas econômicos. $\mathrm{O}$ economista monetário não tem de lidar com entidades universais como volume total de trocas ou quantidade total de dinheiro em todo o sistema econômico. De menos ainda pode lhe servir a nebulosa metáfora "velocidade de circulação". Ele, antes de tudo, tem de se conscientizar de que a demanda por moeda surge das preferências individuais dentro de uma sociedade de mercado. A demanda por moeda existe justamente pelo fato de que todos os indivíduos desejam, a qualquer momento, manter consigo certa quantia de dinheiro, às vezes mais, às vezes menos.

Não é correto dizer que a moeda está no sistema econômico ou na economia nacional. Como também é incorreto dizer que a moeda está circulando. A moeda nunca está simplesmente no sistema econômico, e nem nunca está simplesmente circulando. Todo o dinheiro disponível está sempre em posse de alguém. Uma parte desse dinheiro pode no máximo ser transferido de uma pessoa a outra; mas a todo o momento ele está em posse de alguém e é parte de seus haveres. São as decisões dos indivíduos em relação à magnitude de seus encaixes que irão constituir o fator supremo da formação do poder de compra da moeda.

É impossível que mudanças na quantidade de moeda e na demanda por encaixes ocorram no sistema econômico como um todo se não tiverem antes ocorrido nas famílias. Essas 2 A ideia de que a moeda não é neutra já aparece em Cantillon, que é para alguns o verdadeiro fundador da ciência econômica moderna. Num livro que aparece em 1730, intitulado Ensaio sobre a natureza do comércio em geral, Cantillon mostra como que o aumento da quantidade de moeda não afeta os preços de forma uniforme, tendo em vista que o efeito deste aumento sobre a economia real se dá por sucessivos estágios, num processo que inevitavelmente converge para uma estrutura de preços relativos distinta daquela que havia antes da mudança no estoque de moeda. Isso ficou conhecido pelo famoso efeito Cantillon, logo percebido por Hume (1752). 
mudanças individuais jamais ocorrem com todos os indivíduos ao mesmo tempo e no mesmo grau. Consequentemente, elas jamais afetam o julgamento de valor desses indivíduos ao mesmo tempo e no mesmo grau. Tanto a fórmula extremamente simples da velha teoria quantitativa da moeda quanto a da economia matemática contemporânea, segundo a qual os preços, todos os preços, sobem ou caem na mesma proporção do aumento ou da diminuição da quantidade de moeda, estão agora desacreditadas.

Para simplificar nossa análise, voltemos para o caso da inflação monetária. A quantia adicional de dinheiro que entra na economia não vai parar diretamente nos bolsos de todos os indivíduos, muito menos uniformemente. Dentre os beneficiados que recebem primeiramente essa nova quantia, nem todos recebem a mesma quantia e nem todos reagem da mesma forma à mesma quantia que recebem. Aqueles primeiros beneficiados, no caso do ouro, os proprietários das minas; no caso de papel-moeda governamental, o Tesouro ou os bancos, têm agora um efetivo em caixa maior do que antes, o que os permite ofertar mais dinheiro no mercado em troca dos bens e serviços que desejam adquirir.

Essa quantia adicional de dinheiro que eles ofertam no mercado pressiona os preços e salários para cima. Mas não são todos os preços e salários que sobem; apenas os desses setores que primeiro receberam o novo dinheiro em troca de seus bens e serviços. E mesmo esses preços e salários que subiram, não sobem no mesmo grau. Um raciocínio simples ajuda a ilustrar o porquê isso ocorre dessa maneira.

Por exemplo, se o dinheiro adicional for gasto com obras públicas, apenas os preços de algumas mercadorias e apenas os salários de alguns tipos de trabalho irão subir, sendo que os de outras áreas irão permanecer inalterados ou podem até mesmo cair temporariamente. Eles podem cair porque agora há no mercado alguns grupos de indivíduos cuja renda não aumentou, mas que, entretanto, são agora obrigados a pagar mais pelas mesmas mercadorias de antes, no caso, aquelas vendidas pelos indivíduos que foram os primeiros beneficiados pela inflação. Ao serem obrigados a pagar mais por determinados bens e serviços, eles passam a consumir menos de outras áreas, o que pode gerar essa queda temporária de preços.

Assim, as mudanças nos preços em consequência da inflação começam apenas com algumas mercadorias e serviços, e depois vão se difundindo mais vagarosamente de um grupo para outro. Leva-se tempo até que essa quantia adicional de moeda tenha perpassado toda a economia e exaurido todas as possibilidades de mudanças de preço. Mas, mesmo ao final do processo, os vários bens e serviços da economia não foram afetados no mesmo grau. Esse processo de progressiva depreciação monetária alterou a renda e a riqueza dos diferentes grupos sociais. Enquanto o processo de depreciação estiver ocorrendo, enquanto a quantia adicional 
de dinheiro não tiver exaurido todas as suas possibilidades de influenciar os preços e enquanto ainda houver preços inalterados - ou ao menos ainda não alterados completamente - haverá na comunidade alguns grupos favorecidos e alguns grupos prejudicados.

Ou seja, os primeiros a receber o novo dinheiro obtiveram ganhos específicos; eles são os exploradores. Os últimos a receber o novo dinheiro são os perdedores, os explorados, de cujos bolsos saem os ganhos extras obtidos pelos exploradores. Enquanto durar o processo de inflação, estará havendo uma alteração contínua na renda e na riqueza dos indivíduos. Um grupo social ganha à custa de outros. Quando todas as alterações de preços em decorrência da inflação estiverem consumadas, pode-se dizer que ocorreu uma transferência de riqueza entre os grupos sociais. Há agora no sistema econômico uma nova dispersão de riqueza e renda, e nessa nova ordem social os desejos dos indivíduos serão satisfeitos em graus relativamente distintos; graus esses mais discrepantes em relação àqueles da ordem anterior. Os preços nessa nova ordem social não podem simplesmente ser um múltiplo dos preços anteriores. Não é sem razão que os processos de inflação acelerada penalizam de forma severamente desigual os diferentes grupos sociais ${ }^{3}$.

As consequências sociais de uma alteração no poder de compra da moeda são duplas. Primeiro, como o dinheiro é o padrão no qual se realizam os pagamentos futuros, as relações entre credores e devedores são alteradas. Segundo, como as mudanças no poder de compra não afetam todos os preços e salários ao mesmo tempo e no mesmo grau, há uma redistribuição de riqueza e renda entre os diferentes grupos sociais. De todas as propostas de se tentar estabilizar o poder de compra da moeda, o grande erro é não levar em consideração essa segunda consequência. Podemos dizer que a teoria econômica em geral não presta muita atenção a esse detalhe. No pouco que prestou, ela o considerou principalmente em termos de qual seria a consequência de uma inflação monetária para o comércio exterior de um país. Mas essa é apenas uma aplicação específica de um problema de extensão muita mais vasta.

Ora, a política monetária, ao alterar os preços relativos, modifica os sinais emitidos pelos preços. No caso de uma expansão monetária, estes sinais apontam para a redução dos lucros das empresas que produzem para consumo corrente e para o aumento dos lucros da produção de bens para consumo futuro. Alteram-se, portanto, as taxas de retorno sobre as várias combinações de capital. Os retornos nos estágios de produção mais próximos do consumo caem, enquanto crescem os retornos nos estágios de produção mais afastados do consumo; recursos não específicos deslocam-se dos primeiros para os segundos; vai diminuindo a produção de

3 Bresciani-Turroni descreve magistralmente as consequências sociais do fenômeno da hiperinflação ocorrida nos anos 20 na Alemanha. 
bens de consumo, ao mesmo tempo em que os padrões de produção de bens de capital vão sofrendo alterações, passando-se a produzir bens que se adaptem à estruturas de produção que abarquem mais estágios do que anteriormente. Para que esses investimentos se completem até o estágio dos bens de consumo final, deverão ser subtraídos mais recursos do consumo, o que significa que a produção de bens de ordens mais baixas deverá manter-se em queda, até que a nova estrutura de produção se complete.

O processo descrito é autorreversível: na medida em que as rendas dos titulares dos fatores de produção aumentam (em decorrência da expansão monetária), cresce a demanda por bens de consumo, o que faz com que os preços desses bens, relativamente aos preços dos bens mais afastados do consumo, aumentem. Reverte-se, desta forma, o processo: caem os retornos nos estágios mais afastados do consumo final, enquanto sobem os retornos nos estágios mais próximos do consumo final; recursos não específicos fazem o caminho de volta; os bens de capital, que haviam sido dimensionados para a estrutura de produção anterior, têm agora que ser redimensionados para uma estrutura menos intensiva em capital; surgirão perdas e desemprego, que serão mais fortes nos setores que anteriormente haviam se expandido mais e que, agora, defrontam-se com superproduções. As perdas e o desemprego gerados nada mais são do que a contrapartida das alocações perversas de recursos geradas pela expansão monetária. Ou seja, expansão monetária e recessão são aspectos de um mesmo fenômeno.

\section{DEVE EXISTIR UMA QUANTIDADE ÓTIMA DE MOEDA?}

Iremos mostrar agora que a ideia sobre se manter o crescimento de oferta de moeda a uma taxa fixa carece completamente de sentido. Inicialmente, devemos ter em mente que a moeda, mesmo na qualidade de meio fiduciário, deve ser também entendida como uma mercadoria, mantendo seu valor, ainda que não pareça, ligado ao lado real da economia. Isso é garantido pelo teorema da regressão ${ }^{4}$ (MISES, 1912, p. 491-500). Sendo assim, tanto a quantidade de moeda como seu preço (poder de compra) devem ser determinados pela interação entre a

4 A moeda é demandada por possuir um poder de compra pré-estabelecido. Portanto sua utilidade depende do seu preço de mercado, que decorre de que ela tem um preço, ou poder de compra, em termos dos demais bens. Mas se a demanda, portanto, a utilidade do dinheiro, depende do seu preço pré-existente, como pode o preço ser explicado pela demanda? Mises resolveu este aparente raciocínio circular também conhecido como círculo austríaco usando o teorema regressivo da moeda. De acordo com este teorema, a procura por moeda é determinada, não pelo poder aquisitivo de hoje (o que implicaria o referido raciocínio circular), mas antes pelo conhecimento que os agentes formam baseando-se na sua experiência sobre o poder aquisitivo que a moeda teve ontem. Por sua vez, o poder aquisitivo de ontem é determinado por uma procura por moeda que se formou tendo por base o conhecimento existente anteontem relativo ao seu poder aquisitivo. E assim sucessivamente, até chegar àquele momento da história no qual, pela primeira vez, uma determinada mercadoria que começou a ter também procura como meio de troca. 
demanda e a oferta de moeda da economia. Deste modo, como não tem sentido determinar uma taxa de crescimento constante para qualquer bem, também não tem sentido estabelecer algo assim para a oferta de moeda.

A principal função do dinheiro é simplesmente servir como meio de troca. Deve ser entendido que o dinheiro não sustenta nenhuma atividade econômica real, visto que isso é suportado pelos serviços e bens reais poupados. Ao cumprir o seu papel de meio de troca, o dinheiro apenas facilita o fluxo de bens e serviços. Como já fora colocado, historicamente vários bens foram utilizados como meio de troca. Através de um contínuo processo seletivo ao longo de milhares de anos, as pessoas se decidiram pelo ouro como o meio geral de troca. Muito embora os economistas do mainstream aceitem isso como fato, eles negam a capacidade do ouro ou de qualquer outro bem servir como dinheiro nos sistemas monetários modernos. Segundo eles, a oferta de ouro seria inadequada frente a uma economia em contínuo crescimento. Quanto a isso, podemos afirmar que o que importa na demanda por dinheiro é o seu poder de compra. Sobre isso, Mises escreveu:

Os serviços que o dinheiro fornece estão condicionados pela grandeza do seu poder de compra. Ninguém quer manter como encaixe um número definido de pedaços de dinheiro ou um peso definido de dinheiro; o que todos querem manter como encaixe é uma quantia definida de poder de compra. (MISES, 1949).

Em um livre mercado, similarmente ao que ocorre com outros bens, o preço do dinheiro é determinado pela oferta e demanda. Assim, se houver menos dinheiro, seu valor de troca irá aumentar. Inversamente, o valor de troca irá declinar quando houver mais dinheiro. $\mathrm{Ou}$ seja, dentro da estrutura de livre mercado, não é possível haver algo como "pouco" ou "muito" dinheiro. Desde que o mercado seja livre para encontrar seu equilíbrio, não há como haver qualquer escassez de dinheiro. Consequentemente, uma vez que o mercado tenha escolhido uma determinada commodity para servir como dinheiro, o atual estoque dessa commodity será suficiente para servir como dinheiro (se não fosse, o mercado simplesmente não a escolheria). Portanto, em um livre mercado, toda essa ideia de uma taxa ótima de crescimento da oferta monetária é absurda.

\section{REFERÊNCIAS}

BRESCIANI-TURRONI, C. Economia da inflação: o fenômeno da hiperinflação alemã nos anos 20. Rio de Janeiro: Expressão e Cultura, 1989.

FISHER, I. The theory of interest. New York: The Macmillan Co., 1930. 
FISHER, I. The purchasing power of money. New York: The Macmillan Co., 1911.

FISHER, S. Long-term contracts, rational expectations and the optimal money supply rule. Journal of Political Economy. Chicago, v. 85, n. 1, p. 191-206, February 1977.

FRIEDMAN, M. A theoretical framework for monetary analysis. Journal of Political Economy. Chicago, v. 78, p. 193-238, March/April 1970.

FRIEDMAN, M. A program for monetary stability. New York: Fordham University Press, 1963 .

FRIEDMAN, M. The role of monetary policy. American Economic Review. New York, v. 58 , n. 1, p. 1-17, mar. 1968.

HUME, D. Of money. In: MILLER, E. F. (Ed.). Essays, moral, political and literary. Indianapolis: Liberty Classics, 1952.

HUME, D. Of interest. In: MILLER, E. F. (Ed.). Essays, moral, political and literary. Indianapolis: Liberty Classics, 1952.

KEYNES, J. M. The theory of employment, interest and money. London: Palgrave Macmillan, 1936.

LUCAS, R. E. J. Nobel lecture: monetary neutrality. Journal of Political Economy, v. 104, n. 4, p. 661-682, August 1996.

LUCAS, R. E. J.; RAPPING, L. Real wages, employment, and inflation. Journal of Political Economy, Chicago, v. 27, n. 105, p. 721-754, February 1960.

LUCAS, R. E. J.; RAPPING, L. Price expectations and the Phillips curve. American Economic Review, New York, v. 59, n. 3, p. 342-350, June 1969.

MCCANDLESS, G. T.; WEBER, W. Some monetary facts. Federal Reserve Bank of Minneapolis Quarterly Review, Minneapolis, v. 19, n. 3, p. 2-11, 1995.

ROTHBARD, M. N. Man, economy and state. United States: Ludwig von Mises Institute, 1983.

VON MISES, L. Human action: a treatise on economics. United States: Ludwig von Mises Institute, 1949.

VON MISES, L. The theory of money and credit. German: Page \& Co., 1912. 
